\title{
Role of Pharmacist in Disaster Management: A Quantitative Content Analysis Approach
}

Muhammad Ahmer Raza, MS, PharmD ${ }^{1,2}$; Shireen Aziz, MS, Pharm ${ }^{3,4}$; Misbah Noreen, MPhil, PharmD ;

Shahid Masood Raza, PhD, MPhil, BPharm ${ }^{1,4,5}$

${ }^{1}$ Faculty of Pharmacy, The University of Faisalabad, Punjab, Pakistan

${ }^{2}$ Department of Pharmacy Practice, University of Lahore, Punjab, Pakistan

${ }^{3}$ School of Pharmacy, Zhengzhou University, Henan, China

${ }^{4}$ Faculty of Pharmacy, University of Sargodha, Punjab, Pakistan

${ }^{5}$ School of Pharmacy, Tongji Medical College, Huazhong University of Science and Technology, Hubei, China

\begin{abstract}
Background: Little attention has been given to characterizing the roles of pharmacists in disasters even though the importance of pharmacists' involvement is widely acknowledged. Objective: We amid to review a broad range of pharmacists roles in disasters and their response by numerous reports in the literature. Method: A quantitative content analysis technique was used to gather data consisting of words and phrases from literature regarding pharmacists' roles and their response in disasters. Results: A total of 106 reports were reviewed and screened based on titles and abstracts. Of these, only 20 studies were determined to meet the eligibility criteria for discussion. A total of 7 natural disasters (pandemics, tornadoes, fires, earthquakes, floods, hurricanes and storms) were found in the literature. Roles were classified using the Setlak classification scheme, which includes descriptors such as pharmaceutical supply, patient management, policy coordination, and response integration. Pharmaceutical supply was remains the pharmacists' preferred role. Conclusion: It is evident from the literature that pharmacists are uniquely positioned during disasters to provide healthcare continuity and medication.
\end{abstract}

Keywords: Pharmacist, natural disasters, disaster management

\section{Introduction}

Disasters - natural or man-made - occurring since the existence of human beings lead serious and negative outcomes in terms of health. Disaster consider a public health problem has been defined by World Medical Association as "A disaster is the sudden occurrence of a calamitous, usually violent, event resulting in substantial material damage, considerable displacement of people, a large number of victims and/or significant social disruption or a combination thereof" ${ }^{\prime 1]}$. United Nations' of International Strategy for Disaster Reduction (UN/ISDR) defines a disaster as "calamity" or a "catastrophic" event that causes serious destruction in the functioning of a community or society with widespread human, material, economic, and/or environmental loss [2]. According to World Health Organization (WHO), natural hazards from emergencies impact approximately 190 million people directly, leading to more than 77,000 deaths annually. Furthermore, the WHO recorded 1200 outbreaks in 168 countries during the period 2012-2017, taking into account new or reappearing infectious diseases ${ }^{[3]}$. In 1918, the H1N1 virus caused an influenza pandemic that the Centers for Disease Control and Prevention (CDC) described as the harshest and most severe pandemic in recent history. It is estimated that this virus infected approximately one-third of the world's population and caused more than 50 million deaths worldwide ${ }^{[4]}$.

\section{Corresponding author:}

Shahid Masood Raza, PhD, MPhil, BPharm

School of Pharmacy, Tongji Medical College, Huazhong University of Science and Technology Hubei, China; Email: shahipharmacist@gmail.com
Disasters present unique challenges and opportunities to the medical community ${ }^{[5]}$. During a disaster, health can be affected severely for various reasons, including the performance of healthcare professionals and their responses to unexpected challenges. Pharmacists or other pharmaceutical personnel have a history of their role in disasters. Over the years, pharmacists have become known as prescription checkers and medication dispensers. As critical these roles are, however, the unique situations disaster create require pharmacists to play nontraditional roles involving decision-making in therapeutic protocols; extended authority for clinical pharmacists in hospitals; and additional services provided in community pharmacies such as administering vaccinations, medication mail delivery, and pharmaceutical care for people affected by the disaster ${ }^{[6]}$.

Pharmacists are serving for meeting the needs for drugs of the society and are trying to sustain such services in the events of disasters. They are uniquely positioned during disasters to provide healthcare continuity and medication management to affected communities. Pharmacists play a very important role in the accurate determination, provision, and use of drugs which are of particular importance in terms of medical care used by disaster victims. It has been acknowledged that pharmacists are the most widely distributed healthcare professional, being more accessible than supermarkets, banks, or medical centers ${ }^{[7]}$.

The role of pharmacists in community pharmacies and hospital settings can be seen during the current ongoing coronavirus disease 2019 (COVID19) disaster around the globe. An extensive range of new responsibilities has been introduced in 
Europe and the U.S to expand the legal roles of pharmacists to fight an ongoing COVID19 disaster. Pharmacists in Australia are receiving prescriptions through mails/faxed/email, and phone messages for home delivery services. Pharmacists promoted social distancing by organizing pharmacies in such a way as to make it difficult for the virus to spread. They designed temporary barriers to limit the number of patients in the pharmacy at any given time and to increase the distance between patients. They played an important role in educating people and patient on how to behave in the pharmacy and, how patients can protect themselves from infection. Pharmacists worked with other members of the healthcare team and refer patients' chronic disease-related issues to them. They also provided additional information to patients having associated chronic diseases and educate them to perform self-monitoring [8-10].

The purpose of this article was to review a broad range of pharmacists' functions in disasters and their response by numerous reports in the literature.

\section{Methods}

\section{Search strategy}

The units of analysis and observation were journal articles. Data for this review were identified by a structured review of 'PubMed' 'Medline', 'Cumulative Index to Nursing and Allied Health Literature (CINAHL), 'International Pharmaceutical Abstracts (IPA), 'Sociological Sources' including socilNDEX and Social Work Abstracts. The following keywords were used: 'Pharmacist' 'Pharmacist roles' 'Natural Disasters' 'Pharmacist and Natural Disasters' 'Pharmacist and Disaster Management'. All papers reviewed were written in the English language. The included papers were quantitative studies that analyzed pharmacists' roles and classified using the Setlak classification scheme $^{[11]}$ across the areas related to pharmaceutical supply, patient management, response integration and policy coordination during disasters. The last search was performed in July 2020 which was based on COVID19. All studies were screened based on titles and abstracts to exclude irrelevant articles and the remaining full-text reports were further examined to determine whether they met the inclusion criteria.

\section{Eligibility criteria for inclusion}

Studies conducted to examine or report the role of pharmacists in natural disasters were included and considered eligible for this review. The studied population was community pharmacists, hospital pharmacists, and regulatory pharmacists, those involved in the field of disaster and health, or any combination of the above. Only English studies were included in the review. Studies that did not directly address pharmacists' roles in disasters response and management were excluded. Commentary articles were excluded because these depend on the author or authors' point of view. Partially available reported studies (e.g., abstracts, forms, or articles that were inaccessible online) were also excluded. The three authors (MAR, SA and $\mathrm{MN}$ ) independently reviewed the titles and abstracts of the research findings that met the above keywords. The reviewers agreed to exclude articles that did not meet the aforementioned eligibility criteria, whereas those that met the eligibility criteria based on reviewers' assessments were included for full paper review. Full articles were reviewed independently by each reviewer against the inclusion and exclusion criteria. In case of disagreement between the three reviewers, a fourth reviewer (SMR) who was an expert in pharmacy practice and practice based research was asked to review the disagreement between the authors. However, there were no disagreements between the reviewers during the review process.

\section{Data items extraction and studies quality assessment}

We extracted and recorded data on a Microsoft Excel data extraction sheet. We reviewed the following information in the full-text records: authors and year of publication, the country where the study was conducted, study design, nature of disasters, and pharmacist role and response to the disaster management. Study qualities were evaluated using the Critical Appraisal Skills Program (CASP) checklist ${ }^{[12]}$. (See table 4)

\section{Data analysis}

Natural disasters and pharmacists' roles were examined using the nonparametric Kruskal-Wallis test, and a follow-up multiple comparison procedure (Dunn's test) was run using an online macro compatible with the statistics software ${ }^{[13]}$. Statistical analysis was performed using SAS and descriptive statistics, including counts and percentages, were run using Microsoft Excel. Descriptive statistics such as pie chart and bar chart were used for cumulative percentages of disasters referenced in the literature and cumulative percentage of pharmacist roles in disaster management. Goodness-of-fit analysis was used to calculate the differences between pharmacists' roles and functions in disaster management.

\section{Results}

The electronic search based on the screening of titles yielded a total of 106 reports from 'PubMed' 'Medline', 'CINAHL', 'IPA', 'Sociological Sources' including socilNDEX and Social Work Abstracts. A total of 106 articles were identified as relating to pharmacists' roles during natural disasters; after removing duplicate and non-English articles, 96 articles were screened for eligibility. In total, 80 articles were related to the topic, but only 20 fit the inclusion criteria. In the first screening process, 35 articles were excluded because they were not related to pharmacist role, natural disasters, and pharmacist response to disaster management. In the next step, 25 articles including non-peer-reviewed articles $(n=13)$, review articles $(n=2)$, reports, editorial and commentaries $(n=3)$, and inaccessible online articles $(n=7)$ were also excluded. All the included articles had clear aims and objectives, and describing data sources. The study selection process is illustrated in Figure $\mathbf{1}$. 


\section{Studies quality assessment}

Overall, the studies were generally of a reasonable quality. However, some limitations were noted among the studies, and higher quality studies that contribute to existing knowledge are needed. In some studies, neither the relationship between the researcher and the participants nor their influence on the research was stated explicitly. (See table 4)

\section{Disasters and pharmacist role referenced in the literature}

Numerous references to disasters have appeared in the literature since the early 1960s. A total of 7 natural disasters [pandemics (36\%), hurricanes, tornadoes and storms (47\%), flood and fires (8\%) and earthquakes (9\%)] were found in the literature. Table 1 shows the summary of the natural disasters classification. Figure $\mathbf{2}$ shows the total percentages of disasters referenced in the literature. Table $\mathbf{2}$ shows the summary of natural disasters in literature with bibliographical references. A broad range of pharmacist roles in disaster is described by numerous reports in the literature and organized according to a scheme described by Setlak (2004) ${ }^{[11]}$ : pharmaceutical supply, patient management, response integration, and policy coordination. Table 3 shows the summary of pharmacist roles in disaster management. Pharmaceutical supply (44\%), patient management (20\%), response integration (15\%) and policy coordination (13\%) remained the pharmacists' preferred role. Bar-chart with goodness-of-fit analysis of the weighted counts suggests very significant differences between pharmaceutical supply, patient management, response integration and policy coordination roles. Figure $\mathbf{3}$ shows the cumulative percentage of pharmacist role in disasters referenced in the literature.

\section{Discussion}

A broad range of pharmacist roles and responsibilities in disasters is described by numerous reports in the literature. Pharmaceutical supply has been the primary focus of pharmacy services. Ford et al. (2013) stated that pharmaceutical supply outweighs other roles among roles reported ${ }^{[14]}$. Pharmacists have played significant roles in medication inventory, and coordinating drug transportation and drug wholesaler support in disasters. Pharmacists' efforts to deliver medications in a snowstorm in the Spokane, Washington area necessitated using snowmobile teams to deliver medications to homebound residents ${ }^{[15-17]}$. Similarly, the medicine shortage was one of the main challenging problems during the start of the currently ongoing COVID-19 pandemic. Pharmacists played an important role in overcoming this problem by ensuring the availability of essential medicines by changing the same medicine with different strengths, generic substitution, therapeutic substitution, preparing compounded formulation, and importing the medicine from another country or by purchasing the same medicine from alternative authorized sources (nationally). Pharmacists also played an important role in managing the temporal shortage of antiseptics by compounding antiseptics. This additional responsibility would be a novel step towards minimizing the further spread of pandemic ${ }^{[8,18-20]}$.
An important consideration is the shortage of manpower during a disaster and the need for medical personnel, particularly pharmacists, to be pre-trained to perform an array of duties assumed by other disciplines. Such roles include providing basic cardiac life support and cardiopulmonary resuscitation (CPR) functioning and in the absence of a physician offering medical aid and assisting medical personnel in front-line response activities ${ }^{[21-24]}$. During the sudden acute respiratory syndrome (SARS) epidemic in 2003 that closed many hospitals, emergency clinics, and medical offices in Toronto, Canada, pharmacies that remained open became the city's healthcare centers and pharmacists were the primary care providers. Pharmacists begin to assume duties beyond their traditional scope of practice and done well at the time of crisis with allied health professionals before an event occurred to maximize role flexibility ${ }^{[25]}$.

Pharmacists also assumed several therapeutic and outcomes management roles during disasters. Pharmacists as toxicology consultants and poison specialists managed poisonings and drug overdoses by identifying offending substances and providing antidotal and therapeutic management information to physicians. Specifically, pharmacists obtained a detailed patient history; determine the patient's general medical condition before and after the disaster and the potential for patient education, and document physician approval or unauthorized (non-approved) refills or therapeutic substitutions. A major component of managing therapeutic outcomes involves the basic and widely recognized role of distributing or dispensing medications [21, 26, 27]. Two dramatic accounts of the effects of Hurricane Iniki in 1993 describe pharmacists improvising distribution efforts due to lack of electricity by handwriting prescription labels for patients, documenting activities for insurance reimbursement, and delivering medications to hospitals due to blown windows and water damage inpatient rooms ${ }^{[23,28]}$. An interesting account of pharmacists duties during the anthrax attacks in October 2001 shown how pharmacists were integral in the development and implementation of a mass anthrax prophylaxis clinic as they provided logistical support by repackaging and relabeling bulk medications for dispensing, and dispensed antibiotics to people at risk for developing anthrax-related complications ${ }^{[29]}$. During the SARS crisis in Canada in 2004, community pharmacists served as primary care providers, some diagnosing and prescribing in the absence of physicians. Interviews with pharmacists who maintained health system continuity by keeping their pharmacies open (while physician offices and emergency departments closed) revealed a common theme: non-traditional roles increased considerably, and pharmacists' cross-train with other health professionals (i.e., response integration) before disasters occurs to better prepare the health system when human resources are scarce. Pharmacists in Birmingham, Alabama performed a variety of non-traditional roles after receiving a large influx of Hurricane Katrina evacuees. In addition to meeting an increased demand for 
prescription medications, pharmacist volunteers assisted the medical officer in assessing the health needs of patients at evacuation shelters, triaged patients to healthcare services, treated minor injuries with over-the-counter (OTC) products, and served as the media contact for medication-related issues. Another report describes pharmacists who developed a medical countermeasures algorithm and treating patients using the algorithm in response to the anthrax attacks of $2001^{[25] .}$

Planning has its inherent value and is a form of deterrence, and deterrence is always the best defense. Pharmacists participating in policy development contribute significantly to disaster response efforts. State pharmacists in Alabama, for instance, were able to write and fill prescriptions for a 30-day supply of routine, non-narcotic medications for Hurricane Katrina victims as a result of state policy changes. The American Society of Health-System Pharmacists (ASHP) organization encourages pharmacist participation in disaster planning, particularly coordinating institutional pharmaceutical plans with private, local, state, and federal planners. It also recognized the need for pharmacists to develop first aid, CPR, and basic cardiac life support skills to better integrate with medical responders ${ }^{[30] \text {. }}$

\section{Limitations}

This review had some limitations worth mentioning. First, the review included only articles published in the English language. Second, non-peer-reviewed literature related to disasters was excluded from the analysis. Third, all the articles related to human-made disasters were also excluded.

\section{Conclusion}

Pharmacists have historically played a significant role in disaster management and there are a number of opportunities for pharmacists to bring their unique and innovative perspective, positioning and skills to disaster response and management.

Ethics approval and consent to participate: Not applicable. Consent for publication: All authors approved the manuscript. Availability of data and materials: Not applicable Competing interests: All authors declare no competing interests

\section{Funding: None}

Author contributions: MAR and SA were engaged in reviewing the literature, designing the model, drafting and writing the manuscript. MN and SMR were responsible for the conception and critical revision of the manuscript. All authors have read and approved the final text of the manuscript.

Acknowledgment: We are thankful to our colleagues to address the attention to this issue.

\section{References}

1. Altıntaş, K., Afet ve afet tıbbi ile ilgili temel kavramlar. HAMER Acil ve afet durumlarında sağlık yönetimi içinde, 2013(s 23).

2. Khorram-Manesh, A., Handbook of disaster and Emergency Management. Göteborg: Kompendiet, 2017.

3. World Health Organization. Health Emergency and Disaster. . [cited 2021 30th August]; Available from: https://www.who.int/hac/techguidance/preparednes s/health-emergency-and-disaster-risk-managementframework-eng.pdf.

4. Center for Disease Control and Prevention. Pandemic Influenza. [cited 202128 August]; Available from: https://www.cdc.gov/flu/pandemic-resources/.

5. Hepler, C.D. and L.M. Strand, Opportunities and responsibilities in pharmaceutical care. American journal of hospital pharmacy, 1990. 47(3): p. 533-543.

6. Hogue, M.D., et al., The nontraditional role of pharmacists after hurricane Katrina: process description and lessons learned. Public health reports, 2009. 124(2): p. 217-223.

7. Watson, K.E., et al., Defining pharmacists' roles in disasters: a Delphi study. PloS one, 2019. 14(12): p. e0227132.

8. Merks, P., et al., The legal extension of the role of pharmacists in light of the COVID-19 global pandemic. Research in Social and Administrative Pharmacy, 2021. 17(1): p. 1807-1812.

9. Australian Government Department of Health. Fact Sheet of Corona Virus.; Available from: https://www.health.gov.au.

10. Zheng, S.-q., et al., Recommendations and guidance for providing pharmaceutical care services during COVID-19 pandemic: a China perspective. Research in social and administrative pharmacy, 2021. 17(1): p. 1819-1824.

11. Setlak, P., Bioterrorism preparedness and response: emerging role for health-system pharmacists. American journal of health-system pharmacy: AJHP: official journal of the American Society of HealthSystem Pharmacists, 2004. 61(11): p. 1167-1175.

12. Critical Appraisal Skills Programme, 2018. CASP qualitative checklist. [cited 20216 October]; Available from: http://casp-uk.net/wpcontent/uploads/2018/03/CASP-QualitativeChecklist-2018 fillable form.pd. 
13. Elliott, A.C. and L.S. Hynan, $A S A S^{\circledR}$ macro implementation of a multiple comparison post hoc test for a Kruskal-Wallis analysis. Computer methods and programs in biomedicine, 2011. 102(1): p. 75-80.

14. Ford, H., C.E. Dallas, and C. Harris, Examining roles pharmacists assume in disasters: a content analytic approach. Disaster Med Public Health Prep, 2013. 7(6): p. 563-72.

15. Terriff, C.M. and S. Newton, Pharmacist role in emergency preparedness. Journal of the American Pharmacists Association, 2008. 48(6): p. 702-708.

16. Thompson, C.A., HHS redesigns role of pharmacy personnel in disaster preparedness. 2010, Oxford University Press.

17. Young, D., Pharmacists play vital roles in Katrina response: more disaster-response participation urged. 2005, Oxford University Press.

18. Romano, S., et al., Time-trend analysis of medicine sales and shortages during COVID-19 outbreak: Data from community pharmacies. Research in Social and Administrative Pharmacy, 2021. 17(1): p. 1876-1881.

19. Badreldin, H.A. and B. Atallah, Global drug shortages due to COVID-19: impact on patient care and mitigation strategies. Research in Social and Administrative Pharmacy, 2021. 17(1): p. 1946-1949.

20. Pinto, G.S., et al., FIP's response to the COVID-19 pandemic: Global pharmacy rises to the challenge. Research in Social and Administrative Pharmacy, 2021. 17(1): p. 1929-1933.

21. Levy, D.B., et al., Pharmacist participation in the management of incidents involving hazardous materials. American journal of hospital pharmacy, 1987. 44(3): p. 549-556.
22. Massoomi, F., Pharmacists in the Omaha Metropolitan Medical Response System. American journal of health-system pharmacy, 2005. 62(12): p. 1290-1298.

23. Merges, V., Hurricane Iniki--providing hospital pharmacy services. Hospital pharmacy, 1993. 28(5): p. 393-4, 400.

24. Montello, M.J. and T. Ames, Therapeutic selection during an emergency response. American journal of health-system pharmacy, 1999. 56(3): p. 236-240.

25. Austin, Z., J.C. Martin, and P.A. Gregory, Pharmacy practice in times of civil crisis: The experience of SARS and "the blackout" in Ontario, Canada. Research in Social and Administrative Pharmacy, 2007. 3(3): p. 320-335.

26. Nolin, K., et al., Chempack program: Role of the health-system pharmacist. American journal of health-system pharmacy, 2006. 63(22): p. 2188-2190.

27. Grabenstein, J.D., Public and patient concerns in catastrophic circumstances. American journal of health-system pharmacy, 2002. 59(10): p. 923-925.

28. Miller, C., Hurricane Iniki--providing Prescription Service in a Clinic. Hospital pharmacy, 1993. 28(5): p. 401-403.

29. Haffer, A.S., et al., 2001 anthrax crisis in Washington, $D C$ : Clinic for persons exposed to contaminated mail. American journal of health-system pharmacy, 2002. 59(12): p. 1189-1192.

30. Chin, T.W., et al., Severe acute respiratory syndrome (SARS): the pharmacist's role. Pharmacotherapy: The Journal of Human Pharmacology and Drug Therapy, 2004. 24(6): p. 705-712. 
Figure 1: Study selection process

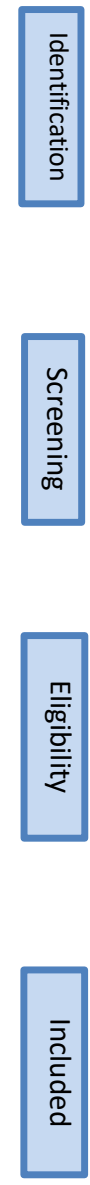

PubMed, Medline, CINAHL, IPA, socilNDEX: $n=106$

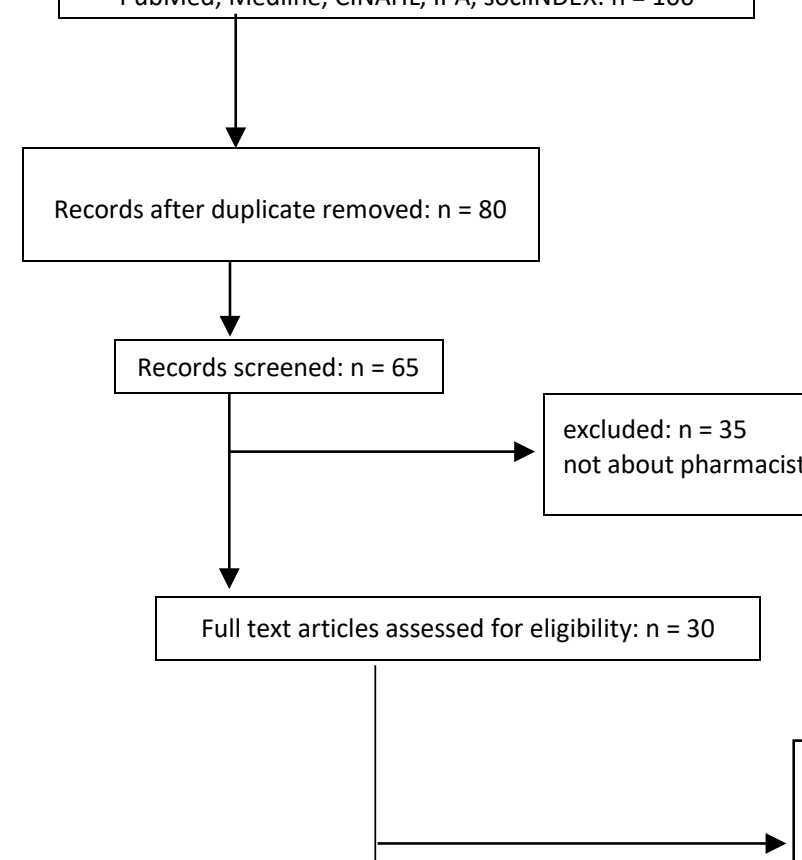

Excluded after reading full text: $\mathrm{n}=25$ Non-peer reviewed articles: $n=13$

Review articles: $\mathrm{n}=2$

Inaccessible online: $\mathrm{n}=7$

Commentaries: $\mathrm{n}=3$

Selected articles: $\mathrm{n}=\mathbf{2 0}$ 
Figure 2: Cumulative percentages of disasters referenced in literature

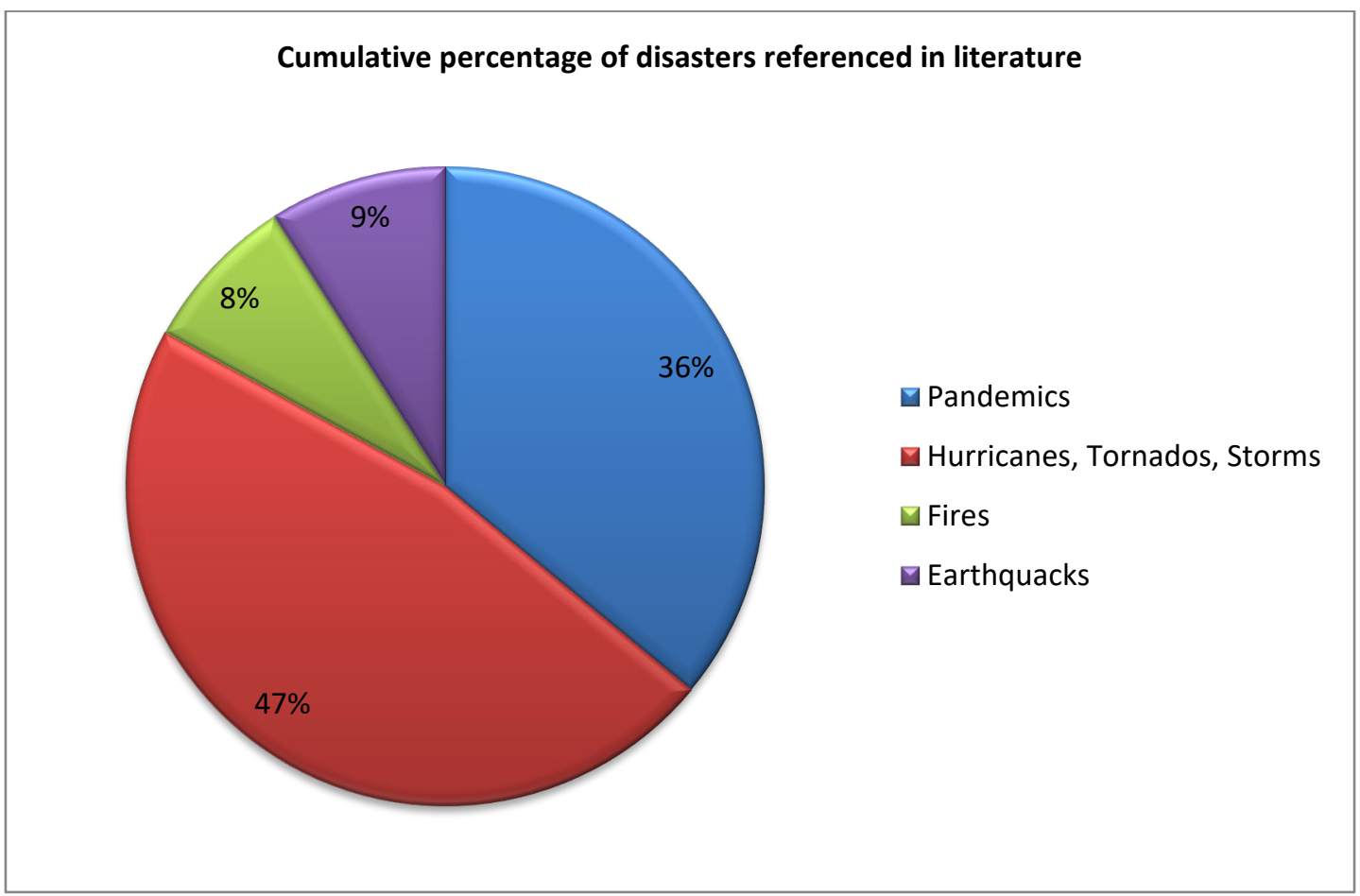

Figure 3: Cumulative percentage of pharmacist role in disasters

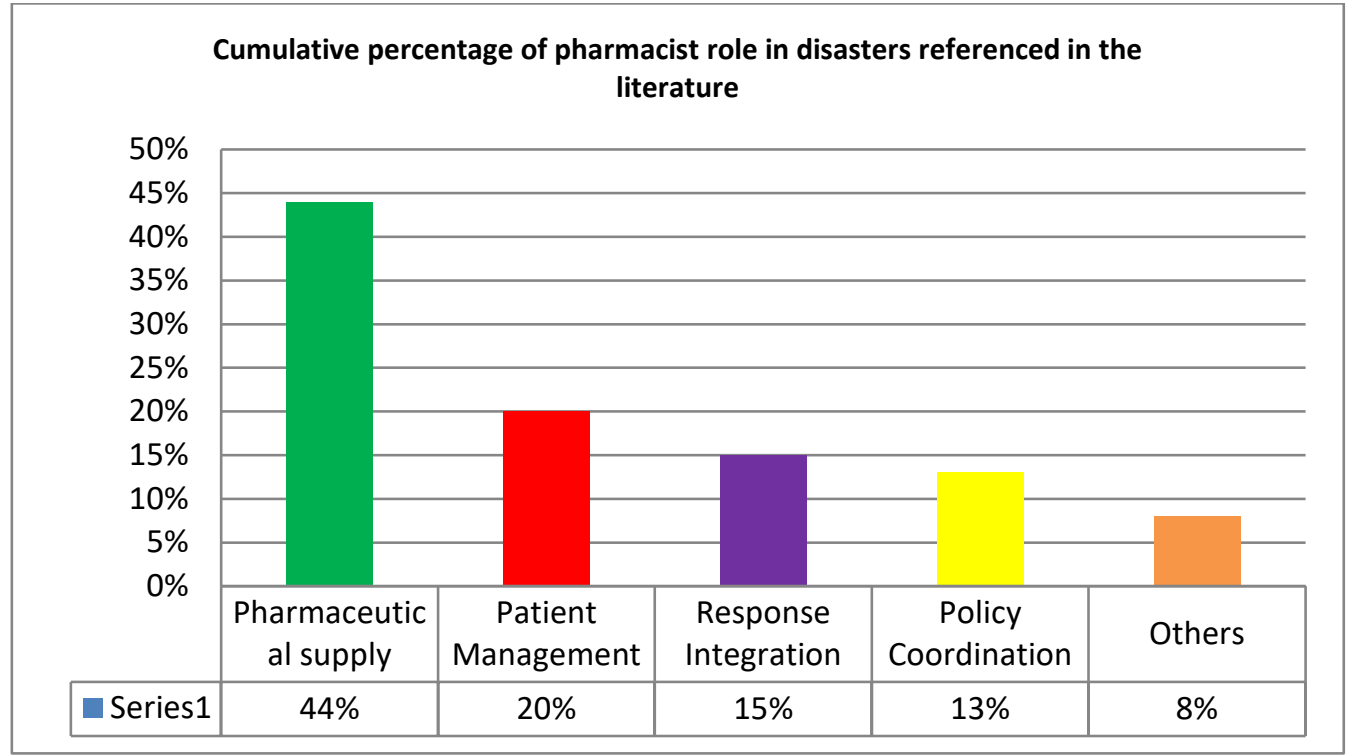


Table 1: Natural disaster classification

\begin{tabular}{|l|l|}
\hline \multirow{4}{*}{ Natural disaster } & Pandemics (H1N1, MERS, COVID19) \\
\cline { 2 - 2 } & Floods \\
\cline { 2 - 2 } & Hurricanes \\
\cline { 2 - 2 } & Fires \\
\cline { 2 - 2 } & Earthquake \\
\cline { 2 - 2 } & Tornados \\
\cline { 2 - 2 } & Storms (rainstorms, windstorms, tropical storms, snowstorms) \\
\hline
\end{tabular}

H1N1: Hemaglutinin1 Neuramidases 1, MERS: Middle East Respiratory Syndrome, COVID19: Corona virus disease in 2019

Table 2: Summary of natural disaster appearing in literature

\begin{tabular}{|c|c|c|c|}
\hline Year & Month & Event & Bibliographical reference \\
\hline 1966 & March, April & Tornado in Jackson, Mississippi and Florida & Pharmacother. 2002; 22(3):271-81. \\
\hline 1979 & September & Anthrax release from Sverdlovsk, USSR & Am J Health-Syst Pharm. 2004; 61:756-58. \\
\hline 1984 & August & Salmonella typhmurium release in Dalles & Hosp Pharm. 1990; 25:523-526. \\
\hline 1989 & September & Hurricane Hugo & Am J Health-Syst Pharm. 2008; 65:904 \\
\hline 1989 & November & Tornado in Huntsville, Alabama & Am Pharm. 1995; NS35 (10):33-34. \\
\hline 1992 & August & Hurricane in Andew and Iniki & $\begin{array}{l}\text { Hosp Pharm. 1993; 28(5):393,394,400. } \\
\text { Ann Pharmacother. 2000; 34:112-18 }\end{array}$ \\
\hline 2001 & October & Anthrax attack in Washington D.C & Am J Health-Syst Pharm. 2004; 61:1167-75. \\
\hline 2002 & March & SARS outbreak in China & Pharmacother. 2004; 24(6):705-12. \\
\hline 2003 & --- & SARS outbreak in Toronto, Canada & Res Soc Adm Pharm. 2007; 3:320-35. \\
\hline 2005 & $\begin{array}{l}\text { August, } \\
\text { September }\end{array}$ & Hurricane in Katrina and Rita & $\begin{array}{l}\text { J Am Pharm Assoc. } 2008 ; 48(6): 702,707 . \\
\text { Ann Pharmacother. } 2002 ; 36: 1282-86 .\end{array}$ \\
\hline 2008 & --- & Tornado and flooding in Lowa & Am J Health-Syst Pharm. 2007; 64:1998-99. \\
\hline 2008 & February & Snowstorm in Washington, D.C & J Am Pharm Assoc. 2008; 48(6):702,707. \\
\hline 2008 & July & Hurricane in Dolly and Ike & J of the Am Pharm Assoc, 48(6), 702,707 \\
\hline 2008 & --- & Flood in Lowa & Hosp Pharm. 1989; 24:697-99. \\
\hline 2009 & --- & H1N1 outbreak & Am J Health Syst Pharm. 2005; 62:220216. \\
\hline 2012 & April & MERS outbreak in Middle East & https://doi.org/10.1016/j.jiph.2017.05.005 \\
\hline 2019 & November & COVID19 in China & http://m.news.cctv.com/2020 \\
\hline
\end{tabular}

COVID19; Corona virus Disease in 2019, SARS; Severe Acute Respiratory Syndrome, MERS; Middle East Respiratory Syndrome 
Table 3: Summary of pharmacist role in disasters

\begin{tabular}{|c|c|}
\hline Patient Management & $\begin{array}{l}\text { Collaborate on medication management } \\
\text { Educate public about therapies } \\
\text { Act to prevent panic and fear } \\
\text { Discourage personal drug stockpiles } \\
\text { Monitor disease progression } \\
\text { Engage in one-on-one patient counseling }\end{array}$ \\
\hline Response Integration & $\begin{array}{l}\text { Ensure proper deployment of drugs } \\
\text { Become well-informed about relevant topics } \\
\text { Develop and maintain first-aid skills } \\
\text { Assist in patient triage and cardiopulmonary resuscitation (CPR) }\end{array}$ \\
\hline Pharmaceutical Supply & $\begin{array}{l}\text { Select therapies for stockpiles and inventories } \\
\text { Maintain effective system of distribution and control } \\
\text { Ensure proper packaging, storing, labeling, etc. } \\
\text { Compile patient records }\end{array}$ \\
\hline Policy Coordination & $\begin{array}{l}\text { Develop guidelines for diagnosis and treatment of disease } \\
\text { Coordinate with state and local boards to avoid redundancy } \\
\text { Incorporate drug expertise in policy decisions at state and local level }\end{array}$ \\
\hline Other & $\begin{array}{l}\text { Prevention } \\
\text { Tele-pharmacy and tele-health } \\
\text { Patient counseling and education at community level } \\
\text { Vaccination and immunization }\end{array}$ \\
\hline
\end{tabular}

Table 4 Critical Appraisal Skills Program (CASP) checklist

\begin{tabular}{|c|c|c|}
\hline Studies quality assessment checklist & Yes & No \\
\hline 1. Was there a clear statement of the aims of the research? & 20 & 0 \\
\hline 2. Was a quantitative methodology appropriate? & 20 & 0 \\
\hline 3. Was the research design appropriate to address the aims of the research? & 20 & 0 \\
\hline 4. Was the recruitment strategy appropriate to the aims of the research? & 15 & 05 \\
\hline 5. Has the relationship between researcher and participants been adequately considered? & 09 & 11 \\
\hline 6. Have ethical issues been taken into consideration? & 12 & 08 \\
\hline 7. Was the data analysis sufficiently rigorous? & 17 & 03 \\
\hline 8. Was there a clear statement of findings? & 16 & 04 \\
\hline
\end{tabular}

